\title{
Correction to: Tempo-spatial patterns of PM2.5 measured using a portable particulate monitor around a mine complex in Canada's Arctic
}

\author{
Wenjun Chen · Sylvain G. Leblanc $\cdot$ H. Peter White (D) Andrea Patenaude • \\ Karin Clark • Bruno Croft · Jody S. Pellissey $\cdot$ Laura Meinert • \\ John Boulanger • Anne Gunn
}

Published online: 18 November 2021

(C) Springer Nature Switzerland AG 2021

\section{Correction to: Environ Monit Assess (2021) 193:560 https://doi.org/10.1007/s10661-021-09376-5}

The original version of this article unfortunately contained an error in one of the author name.

The third author name Peter $\mathrm{H}$. White should be corrected as H. Peter White.

The corrected author name is shown in the author group and affiliation section.

The original article can be found online at https://doi.org/ 10.1007/s10661-021-09376-5.

W. Chen $(\bowtie) \cdot$ S. G. Leblanc $\cdot$ H. P. White

Centre for Mapping and Earth Observation, NRCan,

Ottawa, Canada

e-mail: Wenjun.chen@Canada.ca

A. Patenaude $\cdot$ K. Clark $\cdot$ B. Croft

Environment and Natural Resources, GNWT, Yellowknife,

Canada

J. S. Pellissey $\cdot$ L. Meinert

Wekèezhìi Renewable Resources Board, Yellowknife,

Canada

J. Boulanger

Integrated Ecological Research Ltd, Nelson, Canada

\section{A. Gunn}

CircumArctic Rangifer Monitoring and Assessment

Network, Vancouver, Canada
Publisher's Note Springer Nature remains neutral with regard to jurisdictional claims in published maps and institutional affiliations. 